\title{
Caracterização morfológica de frutos, de sementes e do desenvolvimento pós-seminal de Licania tomentosa (Benth.) Fritsch
}

\author{
Morphological characteristics of fruit, seed e post-seminal development of Licania tomentosa (Benth.) \\ Fritsch
}

\author{
Kênia Leite Monteiro ${ }^{\mathrm{I}}$ Camila de Oliveira' ${ }^{\mathrm{II}}$ Breno Marques da Silva e Silva ${ }^{\mathrm{III}}$ Fabiola Vitti Môro ${ }^{\mathrm{IV}}$ \\ Douglas Antônio de Carvalho
}

\section{RESUMO}

O presente trabalho teve por objetivo descrever a morfologia do fruto, da semente e do desenvolvimento pósseminal de oiti (Licania tomentosa (Benth.) Fritsch.). As sementes e os frutos foram avaliados quanto às dimensões $e$ forma por meio de mensurações com paquímetro digital e observações realizadas em microscópio estereoscópico e microscópio eletrônico de varredura. Os frutos de oiti são drupáceos, elípticos, monospérmicos, carnosos, indeiscentes, com pedúnculos não articulados, epicarpo liso, glabro, de coloração amarela a alaranjada, mesocarpo carnoso, fibroso, coloração amarela a laranja e endocarpo membranáceo, de coloração branca a creme, medindo aproximadamente $6,19 \mathrm{~cm}$ de comprimento, $3,3 \mathrm{~cm}$ de largura, $39,5 \mathrm{~g}$ de massa fresca e 17,3g de massa seca. As sementes são exalbuminosas, de forma elíptica, com tegumento liso, de coloração marrom, de cartáceo a coriáceo, com rafe visível longitudinalmente, micrópila inconspícua e hilo pouco aparente, com cotilédones crassos, elípticos e plano-convexos, de coloração creme a levemente rósea. O embrião é diminuto, reto, central, com eixo embrionário diferenciado em plúmula e eixo hipocótiloradicular. $O$ comprimento, largura e massa fresca e seca das sementes são cerca de 4,07, 2,18cm, 12,7 e 7,2g, respectivamente. A germinação é criptocotiledonar hipógea, com eófilos alterno-dísticos e lanosos, com estômatos paracíticos e duas glândulas na base do limbo ou, raramente no ápice, na face abaxial da folha.

Palavras-chave: oiti, morfologia, plântula, germinação, Chrysobalanaceae.

\begin{abstract}
The objective of the present work was to describe the morphology of fruit, seed and the post-seminal development of "oiti" (Licania tomentosa (Benth.) Fritsch.). The size and shape of seeds and fruits were evaluated with a digital calipter ruler and in stereo-microscope and scanning electron microscope. The fruits are drupaceous, ellipticals, monospermics, succulents, indehiscents, with non articulated peduncle, with smooth and glabrous exocarp of yellow to orange coloration; yellow, succulent and fibrous mesocarp and cream, membranaceous endocarp. The fruits dimensions are approximately $6,19 \mathrm{~cm}$ in length, $3,30 \mathrm{~cm}$ in width, $39,5 \mathrm{~g}$ of fresh mass and $17,3 \mathrm{~g}$ of dry mass. The seeds are exalbuminous, ellipticals, with smooth tegument, with brown coloration, cartaceous to coriaceous, with longitudinally visible raphe, inconspicuous micropyle and inconspicuous hilum, with thick cotyledons, elliptical and plan-convex, with cream to rose color. The embryo is minute, straight, central, with embryonic axis differentiated in plumule and hypocotyl-radicle axis. The length, width and fresh and dry mass of seeds is approximately $4,07 \mathrm{~cm}, 2,18 \mathrm{~cm}, 12,7 \mathrm{~g}$ and $7,2 \mathrm{~g}$, respectively. The germination is criptocotyledonary hypogeal, with alternatedistichous and woolly eophylum, with paracitic stomata and two glands in the base of limb or, rare in the apex, in the abaxial face of leaf.
\end{abstract}

Key words: "oiti", morphology, seedling, germination, Chrysobalanaceae.

'Universidade Federal de Lavras (UFLA), Lavras, MG, Brasil.

"Secretaria do Estado da Educação (SEED), Governo do Estado do Amapá (GEA), Macapá, AP, Brasil.

IIIInstituto de Pesquisas Científicas e Tecnológicas do Estado do Amapá (IEPA), GEA, Rod. JK, s/n., Distrito de Fazendinha, 68900280, Macapá, AP, Brasil. E-mail: silvabms@ hotmail.com. Autor para correspondência.

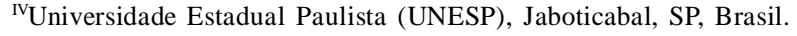




\section{INTRODUÇÃO}

As Chysobalanaceae possuem distribuição pantropical, com 525 espécies (RIBEIRO et al., 1999) em 20 gêneros (SOUZA \& LORENZI, 2005), cujo centro de distribuição e diversidade está representado por cerca de 417 espécies em oito gêneros nos neotrópicos (RIBEIRO et al., 1999). Para Licania registra-se cerca de 214 espécies, das quais 210 são neotropicais, uma africana e três malaias (PRANCE, 2007). No Brasil, ocorrem sete gêneros e aproximadamente 250 espécies, a maioria na Amazônia (JOLY, 1993; SOUZA \& LORENZI, 2005), as quais são árvores, arvoretas, arbustos, raramente subarbustos ou lianas, sendo arbustos ou arvoretas em Hirtella, árvores de subdossel em Licania, Couepia e Chrysobalanus (JOLY, 1993; PRANCE, 2007; SOUZA \& LORENZI, 2005), ou árvores de dossel em Couepia, Licania e Parinari (RIBEIRO et al., 1999). Os autores comentaram ainda que, em geral, a casca viva de Chysobalanaceae é vermelha, grossa e siliciosa (granulosa quando esfregada entre os dedos) e, muitas vezes, com resina avermelhada, sendo que diversas espécies de Licania como $\boldsymbol{L}$. caudata e $\boldsymbol{L}$. latifolia têm raízes escoras e devido à presença de lenticelas grandes e densamente dispostas, o ritidoma de $\boldsymbol{L}$. micrantha e $\boldsymbol{L}$. rodriguessi é de aspecto rugoso.

L. tomentosa (Benth.) Fritsch., conhecida popularmente por oiti e oitizeiro, característica da mata atlântica é uma espécie arbórea, heliófila, perenifólia, frutífera (RIZZINI \& MORS, 1995), com cerca de 8 a 15 metros de altura e de 30 a 50cm de diâmetro (LORENZI, 1992; RIZZINI \& MORS, 1995). A madeira é pesada $\left(0,98 \mathrm{~g} \mathrm{~cm}^{-3}\right)$, dura, resistente, grã direita, textura média para grossa, de longa durabilidade, com alburno quase indistinto (LORENZI (2008). Por proporcionar sombra, o oiti é preferido para plantios em praças, jardins, ruas e avenidas, principalmente nas cidades do Norte e das regiões litorâneas do Brasil (LORENZI (2008); RIZZINI \& MORS, 1995; SOUZA \& LORENZI, 2005), ademaisé utilizada para produção de madeira e em recuperação de áreas degradadas (LORENZI (2008).

Apesar dos múltiplos usos, as informações morfológicas dos frutos, sementes e plântulas de oiti são escassas, mas é inegável que a identificação de espécies florestais por meio dos frutos e das sementes se faz necessária em manejo, conservação da fauna silvestre, estudos ecológicos, paleobotânica e arqueologia (KUNIYOSHI, 1983; OLIVEIRA, 1993; BARROSO et al., 1999). Igualmente, a morfologia da semente, aliada às observações das plântulas, permite fazer a identificação das estruturas, oferecendo, em laboratório, subsídios para a interpretação correta dos testes de germinação, identificação e certificação da qualidade fisiológica. Assim pode auxiliar nos estudos de armazenamento e, no viveiro, contribui para o reconhecimento da espécie e para adequar os métodos de produção de mudas para diversos fins (ARAÚJO \& MATOS, 1991; OLIVEIRA, 1993; AMORIN et al., 1997).

Para $L$. tomentosa, há necessidade de estudos descritivos para auxiliar na identificação de espécies no campo, assim como colaborar na interpretação de testes de germinação e vigor de sementes. Dessa forma, o presente trabalho teve por objetivo caracterizar morfologicamente o fruto, a semente e o desenvolvimento pós-seminal de oiti.

\section{MATERIAL E MÉTODOS}

Os frutos foram coletados de dez árvores matrizes de Licania tomentosa (Benth.) Fritsch., localizadas no Campus da Faculdade de Ciências Agrárias e Veterinárias/FCAV - Universidade Estadual Paulista/UNESP/Campus de Jaboticabal, SP - Brasil. No Laboratório de Morfologia e Anatomia Vegetal DBAA - e no Laboratório de Microscopia Eletrônica, foram efetuadas as análises morfológicas dos frutos, sementes e das fases do desenvolvimento pós-seminal.

Para a descrição biométrica dos frutos e sementes frescas, foram determinadas medidas de comprimento e largura de 150 frutos e número igual de sementes com auxílio de paquímetro digital $(0,1 \mathrm{~mm})$ e régua milimetrada $(1 \mathrm{~mm})$. Posteriormente, determinouse a massa fresca e seca dos frutos e das sementes, sendo a massa seca obtida por meio da secagem em estufa a $70^{\circ} \mathrm{C}$ durante 72 horas (BENINCASA, 2003).

Para a identificação do fruto, foram observadas as seguintes características externas: tipo, consistência, superfície, indumentos, forma, deiscência, coloração, ápice, margem e base (BARROSO et al., 1999; DAMIÃO-FILHO \& MÔRO, 2005). Para as sementes frescas, observaram-se, externamente, tipo, forma, coloração, textura e posição do hilo e, internamente, a forma, coloração, textura, presença ou ausência de 
endosperma e sua forma, tipo e posição do embrião por meio de cortes longitudinais e transversais nas sementes a mão livre, para a visualização em microscópio estreoscópico (BARROSO et al., 1999; DAMIÃO-FILHO \& MÔRO, 2005). Para descrição das fases do desenvolvimento pós-seminal, foram utilizadas 4 repetições de 11 sementes colocadas em caixas plásticas, com areia lavada e esterilizada, umedecida com solução aquosa de bentale (Benomyl 500) 0,1\% e mantidas em casa de vegetação com sombreamento de $75 \%$ a uma temperatura de $22,2 \pm 5,1^{\circ} \mathrm{C}$. A partir do primeiro dia após a semeadura, foram realizadas observações para descrição dos diversos estádios de desenvolvimento, coletando-se amostras das plântulas em fases sequenciais de desenvolvimento, evidenciando-se: desenvolvimento da raiz primária, surgimento de raízes secundárias, crescimento do epicótilo, da gema apical conspícua e o início do crescimento da primeira e segunda folha. A germinação foi caracterizada quanto ao tipo e, as plântulas, quanto à forma, coloração, textura, indumentos, superfície e venação dos protófilos e da folha, filotaxia e presença ou ausência de estípulas (RIBEIRO et al., 1999; DAMIÃO-FILHO \& MÔRO, 2005).

Para as ilustrações em nanquim, os frutos, sementes e plântulas foram desenhados com auxílio de estéreo microscópio com câmara clara acoplada, conforme metodologia de SILVA \& MÔRO (2008). Para a descrição das superfícies adaxial e abaxial das folhas das plântulas, as amostras foram secas e, logo após, analisadas no microscópio eletrônico de varredura, seguindo a metodologia descrita por SANTOS (1996).

Para as descrições morfológicas, foram seguidos os critérios e as terminologias adotados por CORNER (1976); FAHN (1982); RIBEIRO et al. (1999); BARROSO et al. (1999); DAMIÃO-FILHO \& MÔRO (2005). Os dados de biometria de frutos e sementes foram analisados mediante distribuição de frequência.

\section{RESULTADOS E DISCUSSÃO}

Em relação ao comprimento e largura dos frutos de oiti, a maior concentração ocorreu entre 5,5 e 7,0 e 3,0 e 3,6cm, respectivamente (Figura 1A-B). As medidas mínima, média e máxima de comprimento e largura foram observadas em 4,09; 6,19 $\pm 8,1$ e 8,13cm e 2,$10 ; 3,30 \pm 4,7$ e 4,61cm, respectivamente. A maior frequência de frutos, quanto à massa fresca e seca foi observada entre 30 a $50 \mathrm{~g}$ e 10 a $20 \mathrm{~g}$, respectivamente (Figura 1C-D). As massas frescas e secas mínima, média e máxima de frutos de oiti foram observadas em 12,4; 39,5 $\pm 15,7$ e $93,6 \mathrm{~g}$, assim como 5,5; 17,3 $\pm 6,1$ e 37,4g, respectivamente. De forma semelhante, RIZZINI \& MORS (1995) relataram que os frutos de oiti alcançam cerca de $6-8 \mathrm{~cm}$ de comprimento.

Os frutos do oiti são drupáceos, elípticos, monospérmicos, carnosos, indeiscentes e fixados em pedúnculos não articulados (Figura 2). De acordo com
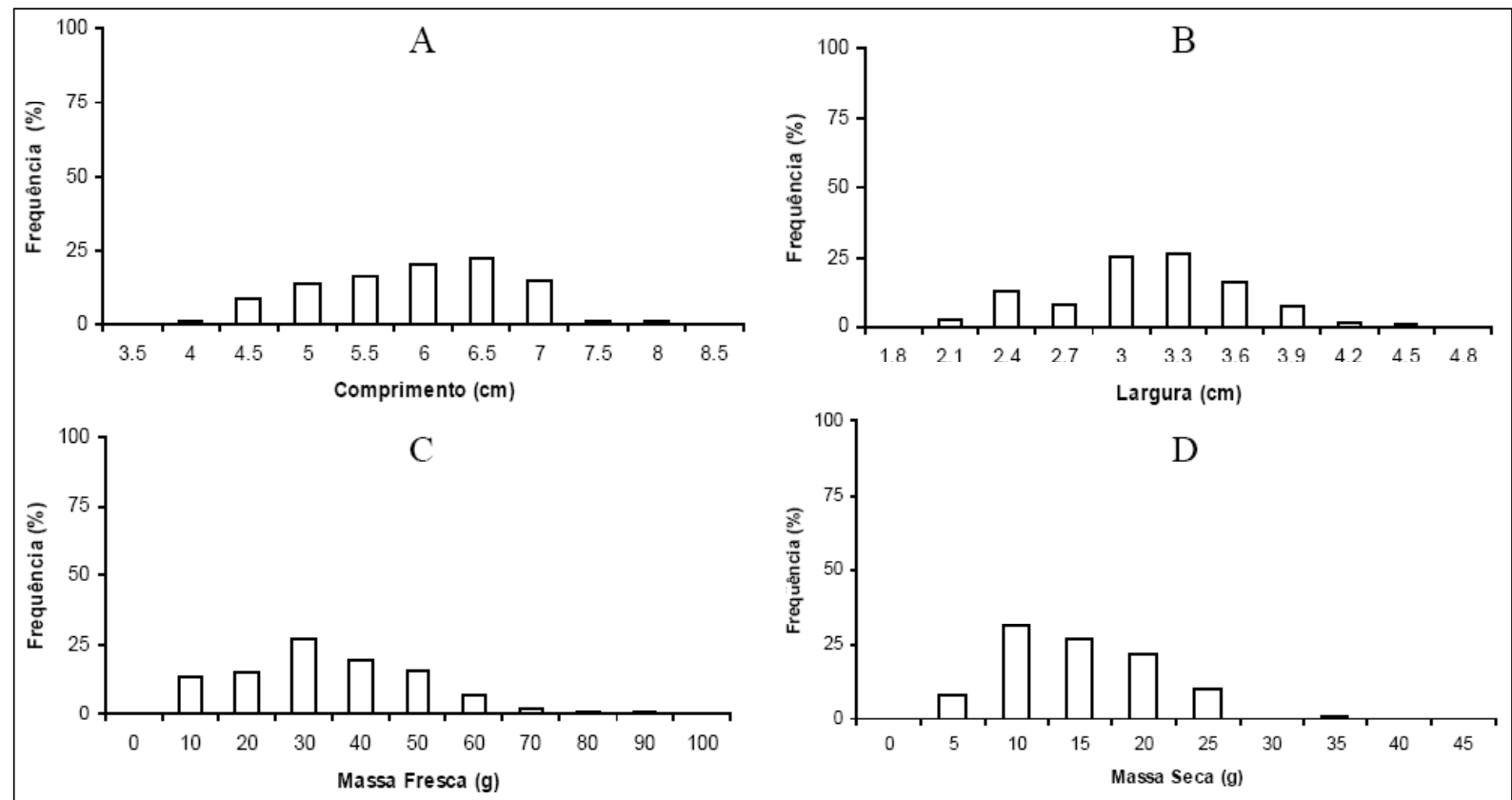

Figura 1 - Comprimento (A), largura (B), massa fresca (C) e massa seca (D) dos frutos de Licania tomentosa (Benth.) Fritsch.

Ciência Rural, v.42, n.1, jan, 2012. 


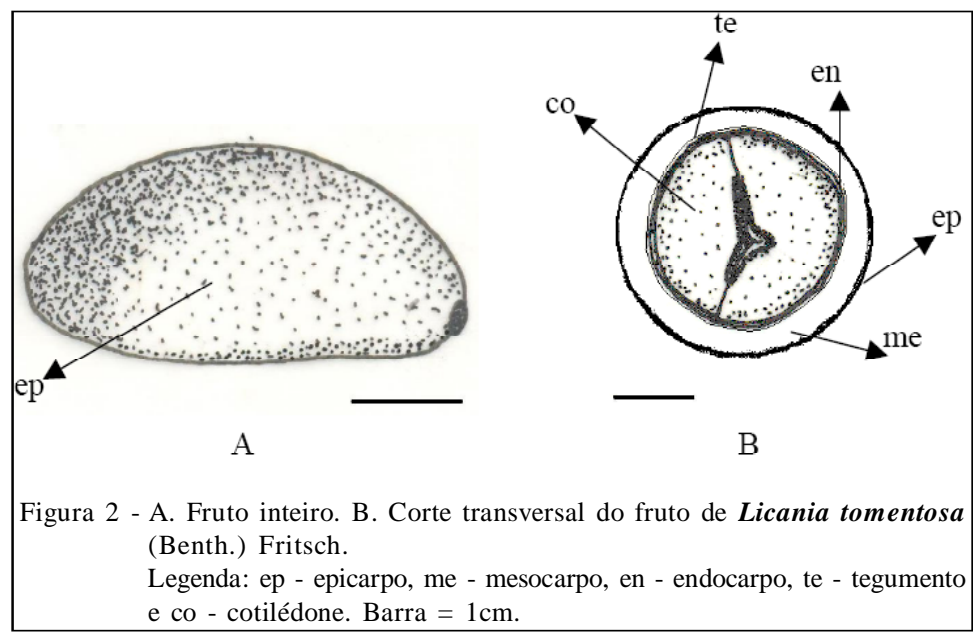

RIBEIRO et al. (1999), o fruto de Hirtella e Licania é uma drupa carnosa.

O pericarpo é formado pelo epicarpo liso, glabro, delgado e, quando maduro, amarelo a alaranjado e, quando imaturo, esverdeado; mesocarpo carnoso, fibroso, espesso, amarelo a alaranjado e endocarpo membranáceo, de coloração branca a creme (Figura 2). De maneira semelhante, RIZZINI \& MORS (1995) relataram como amarelos os frutos de oiti. De acordo com BARROSO et al. (1999); PRANCE (2007), o fruto de Licania é sem placas ou saliências longitudinais de deiscência, endocarpo grosso, duro e lenhoso ou delgado e fibroso, internamente viloso ou glabro.

A maior ocorrência de sementes de oiti foi observada entre 3,4 a 4,6 cm de comprimento, 1,84 e 2,76 cm de largura e 7,0 a 21,0g de massa fresca (Figura 3A-C). As medidas mínimas, médias e máximas das sementes foram observadas em 1,$81 ; 4,07 \pm 7,3$ e $6,29 \mathrm{~cm}$ para o comprimento, 9,$4 ; 2,18 \pm 4,4$ e $3,70 \mathrm{~cm}$ para a largura e 1,$0 ; 12,7 \pm 7,4$ e 53,6g para a massa seca. De acordo com a massa seca da semente, embrião e tegumento e razão de massa seca de embrião/tegumento de sementes de oiti, a maior frequência ocorreu entre 2,5 e 7,5g; 2,5 e $7,5 \mathrm{~g} ; 0,1563$ e $0,6250 \mathrm{~g}$ e 5 e $15 \mathrm{~g} \mathrm{~g}^{-1}$, respectivamente (Figura 3D-G). As medidas mínimas, médias e máximas encontram-se em 1,$03 ; 7,2 \pm 4,0$ e $18,3 \mathrm{~g}$ para a massa seca da semente, 0,$9 ; 6,7 \pm 3,8$ e $17,3 \mathrm{~g}$ para a massa seca do embrião, 0,13; 0,5168 $\pm 0,2178$ e 1,14g para a massa seca do tegumento e 4,$5 ; 12,7 \pm 4,0$ e $26,0 \mathrm{~g} \mathrm{~g}^{-1}$ para a razão de massa seca de embrião/tegumento de sementes de oiti, enquanto LORENZI (2008) observou cerca de 84 sementes $\mathrm{kg}^{-1}$, sendo aproximadamente 11,9 g semente $^{-1}$.

As sementes de oiti são exalbuminosas, de forma elíptica e com funículo aderido, tegumento liso, coloração marrom, de cartáceo a coriáceo, com rafe visível longitudinalmente, micrópila e hilo inconspícuos, com cotilédones elípticos e planoconvexos, crassos, de coloração creme a levemente róseo (Figura 4A e B). As Chrysobalanaceae têm de uma e duas sementes, eretas, quase sem albumina, com testa membranácea e cotilédones plano-convexos, exceto em Chrsysobanalus, cujos cotilédones são de forma côncavo-convexa, formando entre eles um espaço aerífero que, juntamente com a testa fibroesponjosa, indica uma adaptação à dispersão hidrocórica; eixo hipocótilo-radícula reto e diminuto (BARROSO et al., 1999). O embrião de oiti é diminuto, reto, central, com eixo embrionário diferenciado em plúmula e eixo hipocótilo-radicular (Figura 4C e D).

Aos nove dias após a semeadura, a germinação foi marcada pela protrusão da raiz primária, de coloração branca e cilíndrica e, posteriormente, ocorreu o desenvolvimento de raízes secundárias e o desenvolvimento reduzido do hipocótilo, concomitante ao crescimento do epicótilo, levemente lanoso e cilíndrico (Figura 5A). Durante o desenvolvimento do 


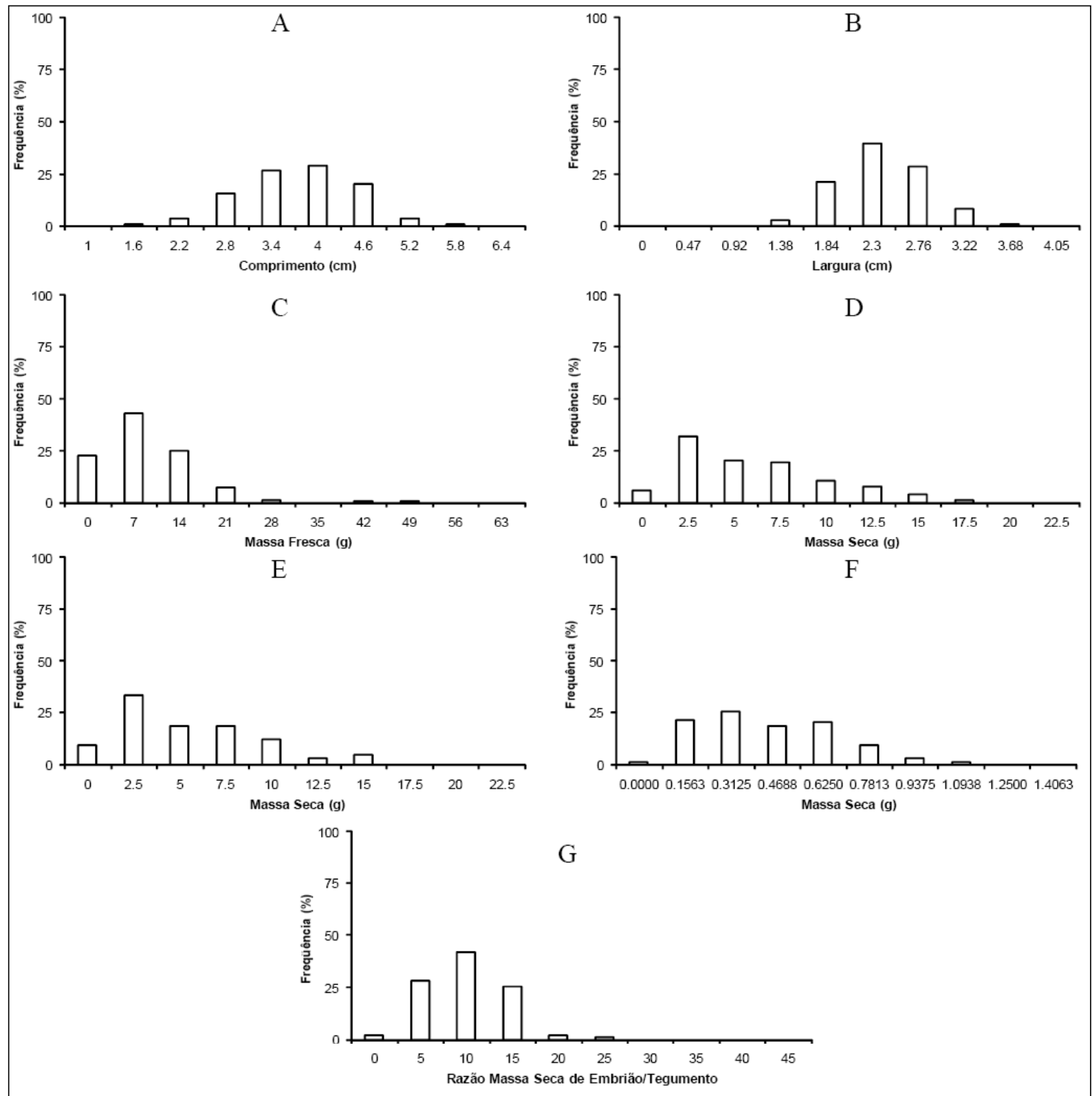

Figura 3 - Comprimento (A), largura (B), massa fresca (C) e massa seca (D) da semente, massa seca do embrião (E), massa seca do tegumento (F) e razão de massa seca do embrião/tegumento (G) de sementes de Licania tomentosa (Benth.) Fritsch.

epicótilo, observa-se a presença de catáfilos alternodísticos e estipulados, levemente recobertos por tricomas lanosos (Figura 5A-B).

As folhas de oiti são lanosas ou tomentosas, com tricomas simples e intensamente enrolados, dando um aspecto de lã nas superfícies adaxial e abaxial (Figura 6 A-B), enquanto a presença de estômatos paracíticos foi observada abaxialmente e, adaxialmente, apenas células epidérmicas irregulares (Figura 6A-D).
Após 17 dias da semeadura, houve o desenvolvimento dos eófilos alterno-dísticos, curtos peciolados, estipulados, oblongo-elípticos a oblongolanceolados, de margem inteira e venação pinada (Figura 5A-D), de coloração verde a pardacenta, devido aos tricomas lanosos ou tomentosos (Figura 6A-B) e com duas glândulas na base ou, raramente, no ápice da face abaxial da folha (Figura 6E-F). De acordo com RIBEIRO et al. (1999); PRANCE (2007), as folhas das 

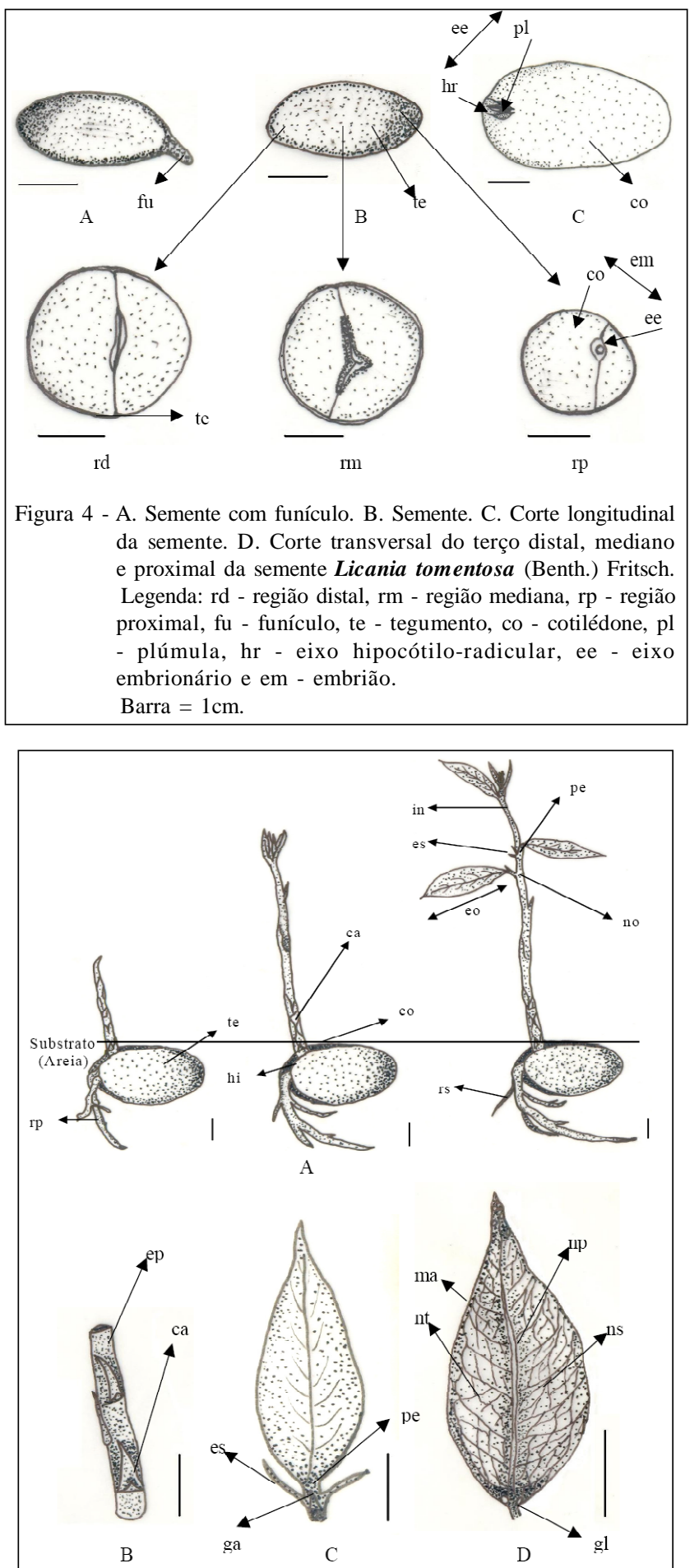

Figura 5 - Etapas do desenvolvimento pós-seminal (A), segmento do epicótilo (B) e face adaxial (C) e face abaxial (D) da folha de Licania tomentosa (Benth.) Fritsch. Legenda: ep - epicótilo, es - estípula, np - nervura principal, ns - nervura secundária, nt - nervura terciária, ma - margem, ga - gema axilar, gl - glândula, pe pecíolo, te - tegumento, rp - raiz primária, rs - raiz secundária, ca - catáfilos, eo - eófilo, pe - pecíolo, hi - hipocótilo, no - nó, in - internódio. Barra $=1 \mathrm{~cm}$. 


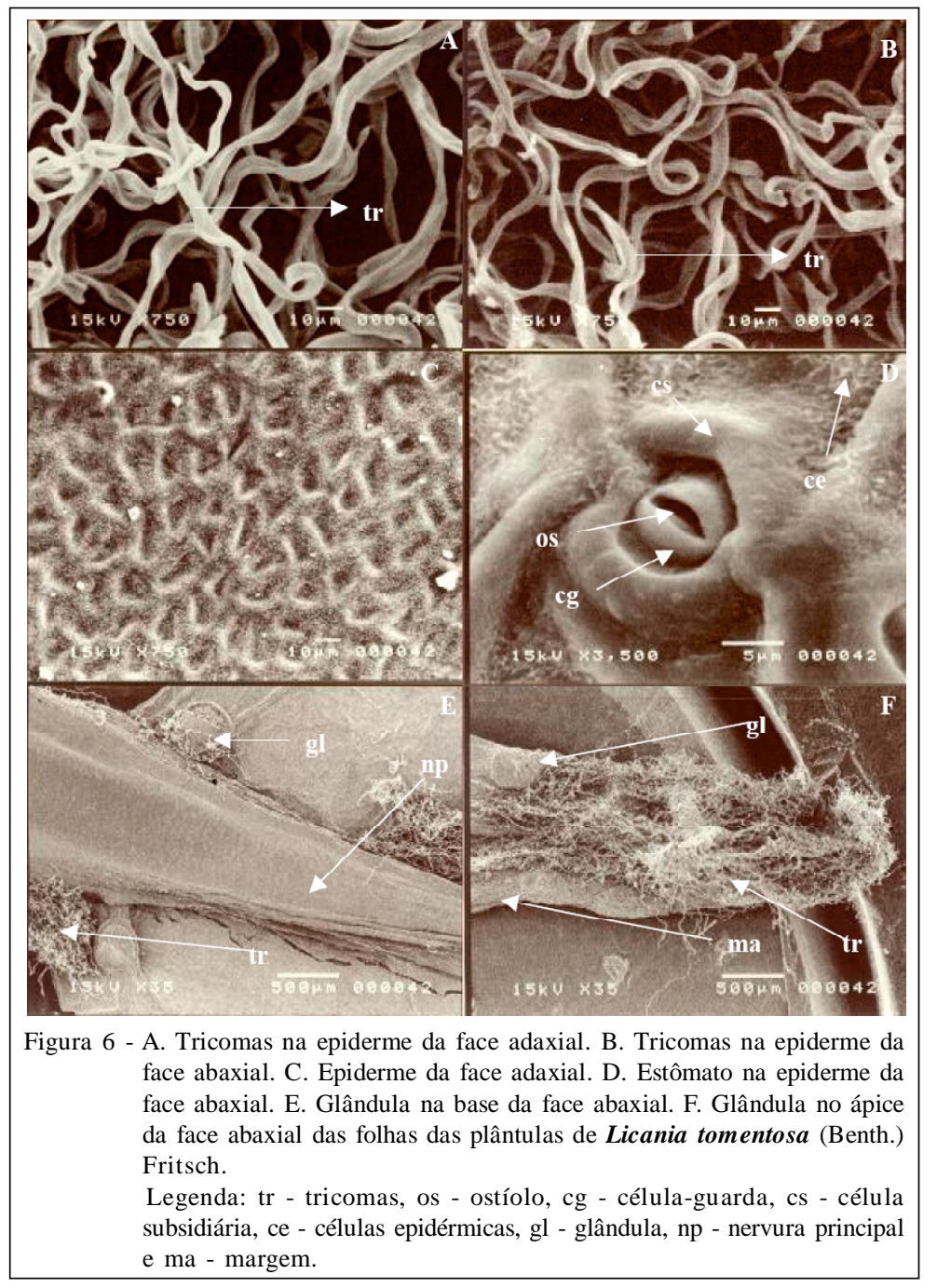

Chrysobalanaceae são alternas, dísticas, duras, de margem inteira, de nervação pinada, frequentemente coriáceas, glabras ou pilosas na face inferior, quase sempre com estípulas pequenas, caducas, largas e persistentes, muitas vezes adnatas ao pecíolo e com glândulas no pecíolo e lâmina (RIBEIRO et al., 1999).

As folhas da Licania são oblongo-elípticas a oblongo-lanceoladas, abaxialmente glabra, quando totalmente expandidas e, às vezes, quando são jovens (em processo de desenvolvimento e/ou expansão), têm indumento lanoso-pubescente caduco e com duas glândulas próximas à base da face abaxial (PRANCE, 2007). No entanto, de acordo com RIZZINI \& MORS (1995); LORENZI (2008), as folhas de oiti são simples, tomentosas em ambas as faces, de 7-14 e de 3-5 cm de comprimento e largura, respectivamente. Em diversas espécies (principalmente do gênero Licania), nota-se a presença de um par de glândulas na base da lâmina, do pecíolo ou espalhadas na lâmina (RIBEIRO et al., 1999).

A germinação das sementes de oiti é criptocotiledonar hipógea (Figura 5A). De forma geral, a germinação de Chysobalanaceae pode ser cripto ou fanerocotiledonar, porém em Licania a germinação é criptocotiledonar (PRANCE, 2007).

Aos 18 dias após a semeadura, as plântulas de oiti tinham folhas simples e alternas, estipuladas e lanosas, com cotilédones crassos e persistentes, raiz primária pivotante e raízes secundárias e terciárias bem desenvolvidas (Figura 5A).

\section{CONCLUSÃO}

Os caracteres morfo-anatômicos de frutos, sementes e das plântulas de oiti possibilitam a sua identificação em in situ. 


\section{REFERÊNCIAS}

AMORIM, I.L. et al. Morfologia do fruto e da semente, e germinação da semente de Trema micrantha (L.) Blum. Cerne, v.3, n.1, p.138-152, 1997. Disponível em: <http://www.dcf.ufla.br/ cerne/artigos/13-02-20099190v3_n1_artigo\%2008.pdf $>$. Acesso em: 27 maio, 2011.

ARAÚJO, S.S.; MATOS, V.P. Morfologia da semente e das plântulas de Cassia fistula L. Revista Árvore, v.15, n.3, p.217223, 1991.

BARROSO, G.M. et al. Frutos e sementes: morfologia aplicada à sistemática de dicotiledôneas. Viçosa: UFV, 1999. 443p.

BENINCASA, M.M.P. Análise de crescimento de plantas: noções básicas. 2.ed. Jaboticabal: FUNEP, 2003. 41p.

CORNER, E.J.H. The seeds of dicotyledons. Cambrige: University, 1976. V.1, 311p.

DAMIÃO-FILHO, C.F.; MÔRO, F.V. Morfologia vegetal. Jaboticabal: FUNEP, 2005. 172p.

FAHN, A. Plant anatomy. 3.ed. New York: Pergamon, 1982. 544p.

JOLY, A.B. Botânica: introdução à taxonomia vegetal. 11.ed. São Paulo: Nacional, 1993. 777p.

KUNIYOSHI, H.S. Morfologia da semente e da germinação de 25 espécies arbóreas de uma floresta com Araucária. 1983. 233f. Dissertação (Mestrado em Ciências) - Universidade Federal do Paraná, Curitiba, PR. Disponível em: <http:// dspace.c3sl.ufpr.br/dspace/bitstream/handle/1884/25193/D\%20$\% 20$ KUNIYOSHI,\%20YOSHIKO\%20SAITO.pdf;jsessionid=3C3EAC
80F4D2210210D17E848171A318? sequence $=1>$. Acesso em: 27 maio, 2011.

LORENZI, H. Árvores brasileiras: manual de identificação e cultivo de plantas arbóreas nativas do Brasil. 5.ed. Nova Odessa: Platarum, 2008. 384p.

OLIVEIRA, E.C. Morfologia de plântulas florestais. In: AGUIAR, I.B. et al. (Eds.). Sementes florestais tropicais. Brasília: ABRATES, 1993. p.175-214.

PRANCE, G.T. Flora da reserva Ducke: Chrysobalanaceae. Rodriguésia, v.8, n.3, p.493-531, 2007. Disponível em: <http://rodriguesia.jbrj.gov.br/rodrig 58 _3/03Chrysobalanaceae.pdf $>$. Acesso em: 27 maio, 2011.

RIBEIRO, J.E.L.S. et al. Flora da reserva Ducke. Guia de identificação das plantas vasculares de uma floresta de terra-firme na Amazônia Central. Manaus: INPA-DFID, 1999. $816 \mathrm{p}$.

RIZZINI, C.T.; MORS, W.B. Botânica econômica brasileira. Rio de Janeiro: Âmbito Cultural Edições, 1995. 248p.

SANTOS, J.M. Microscopia eletrônica de varredura aplicada às ciências biológicas. Jaboticabal: FUNEP, 1996. 56p.

SILVA, B.M.S.; MÔRO, F.V. Aspectos morfológicos do fruto, da semente e desenvolvimento pós-seminal de faveira (Clitoria fairchildiana R. A. Howard. - Fabaceae). Revista Brasileira de Sementes, v.30, n.3, p.195-201, 2008. Disponível em: <http://www.scielo.br/pdf/rbs/v30n3/26.pdf>. Acesso em: 27 maio, 2011.

SOUZA, V. C.; LORENZI, H. Botânica sistemática: guia ilustrado para identificação das famílias de Angiospermas da Flora Brasileira, baseado em APG II. Nova Odessa: Instituto Plantarum, 2005. 640p. 